\title{
LA EVOLUCIÓN DEL SISTEMA EUROPEO DE PROTECCIÓN DE DERECHOS HUMANOS ${ }^{1}$
}

\author{
LUIS LÓPEZ GUERRA \\ Catedrático de Derecho Constitucional \\ Universidad Carlos III de Madrid \\ Juez Emérito del TEDH
}

SUMARIO

I. El carácter evolutivo del sistema europeo de protección de derechos humanos. II. Fase inicial. La elaboración del Convenio Europeo de Derechos Humanos. III. La «fase durmiente» del sistema. IV. La consolidación del Tribunal como órgano esencial de sistema. V. Las reformas del Protocolo 11. VI. La evolución desde el Protocolo 11. La dimensión cuantitativa. VII. La dimensión cualitativa. VIII. ¿El Tribunal Europeo como jurisdicción «cuasi constitucional»? IX. Estados y Tribunal ante la evolución del Convenio.

\section{EL CARÁCTER EVOLUTIVO DEL SISTEMA EUROPEO DE PROTECCIÓN DE DERECHOS HUMANOS}

Posiblemente, la experiencia del sistema creado por el Convenio Europeo de Derechos Humanos sea uno de los mejores ejemplos de la capacidad de las instituciones para adaptarse a los cambios en su entorno, modificando, no sólo su forma de funcionamiento, sino incluso los mismos propósitos que originaron su creación. Los mejores conocedores —en cuanto actores del funcionamiento del sistema - han podido señalar el carácter eminentemente evolutivo del mismo ${ }^{2}$. Como se apuntará, al menos tres fases son visibles en esa evolución; una primera fase, inicialmente orientada a una colaboración interestatal, protagonizada por la Comisión Europea de Derechos Humanos; una segunda fase, centrada en la protección individualizada de los derechos del Convenio por el Tribunal Europeo de

1 El presente trabajo es desarrollo y continuación de algunas publicaciones anteriores del autor: así, «El caracter dinámico del sistema europeo de derechos humanos» publicado en J. C. Carbonell Mateu et. al. (dirs.), Constitución, derechos fundamentals y sistema penal. Semblanzas y estudios con motivo del setenta aniversario del profesor Tomás Salvador Vives Antón, Valencia, Tirant Lo Blanch, 2009; 1178-1188, o «El sistema europeo de protección de derechos humanos» en L. LOPEZ Guerra y A. SAIZ ARnAIz, coords. Los sistemas interamericano y europeo de protección de los derechos humanos, Lima, Palestra, 2015, 57-84.

2 Ver por ejemplo las consideraciones del Presidente del Tribunal de Estrasburgo, J.P. Costa, en La Cour européenne des droits de l'bomme. Des juges pour la liberté, Paris, Dalloz, 2013, pp. 53 y ss. 
Derechos Humanos; y finalmente, parecería apuntarse una tercera, caracterizada por la incipiente adopción de una función cuasi-constitucional del Tribunal de Estrasburgo.

\section{FASE INICIAL. LA ELABORACIÓN DEL CONVENIO EUROPEO DE DERECHOS HUMANOS}

La aprobación del Convenio Europeo de Derechos Humanos en 1950 responde a una serie de características de la situación europea en la posguerra mundial ${ }^{3}$. Por una parte, a finales de los años cuarenta y en una situación de guerra fría, estaba ampliamente extendida la conciencia de la existencia de serios peligros para la propia pervivencia de los regímenes constitucionales de la posguerra. El comienzo de la guerra fría implicaba la división de Europa en bloques con sistemas e ideologías políticas muy distintas, y en el bloque occidental se consideraba una amenaza la extensión de la influencia del bloque liderado por la Unión Soviética, y la posible implantación de regímenes de tipo totalitario. Las experiencias alemana e italiana anteriores a la guerra mostraban la posibilidad de que regímenes de tipo constitucional derivaran a soluciones dictatoriales (sobre todo tras la experiencia del llamado «golpe de Praga» en 1948$)^{4}$ y no cabía excluir que procesos similares se produjeran en las difíciles circunstancias de la posguerra. Era pues comprensible que se buscara una fórmula que hiciera posible una acción conjunta para evitar que ello se produjera.

Esta búsqueda aparecía íntimamente ligada a la consideración de que el mantenimiento de sistemas constitucionales democráticos dependía de la defensa de derechos individuales frente a los abusos del poder; el conocimiento y rechazo de las violaciones masivas de los derechos más elementales por las potencias derrotadas en la guerra había conducido a una reafirmación general (como se reflejó en la Declaración Americana de Derechos y Deberes del Hombre de 1948 y en la Declaración Universal de Derechos Humanos de la Asamblea de las Naciones Unidas) del carácter esencial de esos derechos y de la obligatoriedad de su protección. Una garantía internacional de la democracia implicaba necesariamente una garantía de los derechos básicos de la persona.

Como tercer elemento, la experiencia europea había mostrado que la existencia de regímenes que no respetaban esos derechos suponía también una amenaza para la paz; la garantía de los derechos individuales sería también una garantía de la paz, así como un medio de facilitar para el futuro, una mayor integración entre los países de Europa.

Protección frente a posibles derivas hacia el totalitarismo, defensa de los derechos básicos de la persona, e integración europea eran pues ideas que venían a coincidir y que dieron lugar a diversas iniciativas en el continente europeo: una de ellas llevó a la celebración en Bruselas en 1948, del Congreso del Movimiento Europeo, protagonizado por diversos grupos, presidido por Winston Churchill, en que tomaron parte conocidos europeístas como Salvador de Madariaga o Denis de Rougemont, y que sirvió de iniciativa

3 La obra clave para los primeros cincuenta años del sistema europeo de Derechos Humanos es sin duda (desde una óptica eminentemente británica, reconocida por el autor) la de Ed BATES, The Evolution of the European Convention on Human Rights, Oxford, Oxford University Press, 2010, inestimable fuente de inspiración e información.

4 Sobre este tema, B. Wassenberg, Histoire du Conseil de l'Europe, Estrasburgo, Editions du Conseil de l'Europe, 2013, p 17 y ss; A. H. Robertson, Human Rights in Europe, Manchester, Manchester University Press, 1963, pp. 5-6. 
para que los gobiernos de diversos Estados crearan al año siguiente una organización internacional basada en esas ideas, el Consejo de Europa ${ }^{5}$, dotado de una Asamblea Consultiva y un órgano de tipo ejecutivo, el Comité de Ministros. Y una de las primeras tareas del Consejo fue la elaboración de un instrumento internacional que plasmase esos principios a nivel europeo, y estableciera una garantía internacional de los derechos fundamentales de la persona como base de un sistema democrático.

Ahora bien, y como puede colegirse de lo expuesto, varias perspectivas se ofrecían para la elaboración de ese instrumento, el futuro Convenio para la Protección de los Derechos Humanos y las Libertades Fundamentales ${ }^{6}$. Por una parte, y como expresión de los conceptos clásicos de Derecho Internacional fundados en el protagonismo de los Estados, para muchos de los actores de este proceso el Convenio debería considerarse como un sistema de garantía colectiva entre Estados, protagonizado por éstos, para prevenir la deriva totalitaria de alguno de ellos, mediante la garantía de unos derechos básicos (seis o siete, en expresión de uno de los impulsores más destacado de la iniciativa, Pierre-Henri Teitgen) ${ }^{7}$ por la acción de órganos internacionales; esto es, y como se ha podido definir, el establecimiento de un sistema de «alerta temprana» («early warning system») que impidiera la repetición de los casos italiano y alemán de la preguerra.

Desde luego, y con resultados decisivos para el futuro, ésta no era la única perspectiva presente. Junto a ella, la preocupación por asegurar una protección de derechos fundamentales (esto es, derechos humanos o «derechos del hombre» en la versión francesa, como derechos vinculados indisolublemente a la persona) llevó a que se propusiera el Convenio como una auténtica Carta de Derechos, invocable por los individuos afectados ante instancias internacionales frente a las eventuales vulneraciones por los Estados. Ello suponía una notable innovación en las categorías del Derecho Internacional, en cuanto confería un nuevo protagonismo en este campo al sujeto individual.

La presencia de estas dos perspectivas se hizo evidente en las diversas fases de elaboración del Convenio. Un primer esbozo, elaborado por la Asamblea Consultiva del Consejo de Europa, que ponía el acento en el carácter de «Carta de Derechos» fue profundamente corregido primeramente por un Comité de Expertos nombrados por el Comité de Ministros, y finalmente por una Comisión de Altos Funcionarios; el resultado fue un instrumento que recogía ambos enfoques, pero con evidente predominio de la perspectiva, por así decirlo, «estatal», del Convenio como garantía colectiva entre Estados $^{8}$. El eje del sistema lo constituía una Comisión Europea de Derechos Humanos, encargada de supervisar el respeto por los Estados de una lista de derechos; para ello, los Estados firmantes disponían de la posibilidad de denunciar ante la Comisión las

5 Creado por el Tratado de Londres de 5 de mayo de 1949, incluyendo inicialmente a diez países europeos.

6 Como nota de interés, la designación oficial del Convenio es «Convención para la protección de los derechos humanos y las libertades fundamentales» (Convention for the protection of buman rights and fundamental freedoms, en su versión inglesa) sin referencia a su carácter «europeo». Siguiendo la práctica usual, se empleará la expresión «Convenio».

7 Tomo la referencia de L. Wildhaber, en su momento Presidente del Tribunal, en « The Old Court, the New Court and Paul Mahoney», Human Rights Law Journal, 36, 2016, pp. 292-297, p. 293: ver la nota 4 de su trabajo para la documentación de su referencia.

8 Ver el artículo de la juez E. STEINER «Some reflections on the process which led to the preparation of the European Convention on Human Rights» en La Convention Européenne des droits de l'bomme. Mélanges en honneur de Christos L. Rozakis, Bruselas, Bruylant, 2012, 597-623. También, del juez C. Russo «The Drafting History of the European Convention on Human Rigths and Fundamental Freedoms» en Mainly Human Rights. Studies in Honour of J.J. Cremona, La Valetta, Fondation Internationale Malta, 1999, 234-244. 
vulneraciones del Convenio por otros Estados firmantes, en lo que representaba un recurso interestatal. La Comisión podría en esos casos presentar su informe al Comité de Ministros del Consejo de Europa para que se pronunciara al respecto.

Hasta aquí, el esquema respondía a líneas clásicas del Derecho Internacional. El Convenio incluía, sin embargo, aspectos de la perspectiva, por así decirlo, de garantía individual de derechos, en una forma que ha podido considerar como revolucionaria en el plano del Derecho Internacional ${ }^{9}$. Por un lado, se introducía la posibilidad de un recurso individual, esto es, que las personas afectadas por violaciones del Convenio pudieran presentar sus demandas frente a los Estados ante la Comisión; por otro lado, se creaba un órgano jurisdiccional, el Tribunal Europeo de Derechos Humanos, con capacidad de decisión tanto en recursos interestatales como en recursos individuales.

No obstante, esta segunda dimensión quedaba considerablemente diluida. Como es hoy generalmente reconocido, la idea dominante entre los Estados firmantes era que el Convenio se aplicaría esencialmente en cuanto regulador de relaciones interestatales ${ }^{10}$. No hay que olvidar que en aquellos momentos, algunos Estados europeos (señaladamente Francia y el Reino Unido) poseían extensos imperios coloniales en que la situación de los pueblos colonizados se configuraba, en cuanto a los derechos individuales básicos, como muy diferente de la correspondiente en la metrópoli. El reconocimiento del recurso individual se establecía como optativo, y muy pocos Estados efectuaron esa opción; en la misma línea, también se configuraba como optativa la aceptación de la jurisdicción del Tribunal. Pero además, la legitimación para acudir al Tribunal se restringía notablemente; si bien los individuos podían presentar reclamaciones ante la Comisión frente a los Estados que hubieran admitido el recurso individual, sólo la Comisión, o el Estado afectado, a la vista del informe de ésta, podrían acceder al Tribunal. Por otra parte, la Comisión podía decidir llevar el caso directamente al Comité de Ministros y no al Tribunal. Este se configuraba, así, como una opción residual, y desde luego no abierta directamente a los individuos afectados.

\section{LA «FASE DURMIENTE» DEL SISTEMA}

Es ya lugar común considerar que el funcionamiento del Convenio no respondió, durante mucho tiempo, a los deseos y esperanzas que habían inspirado su creación. Durante algunos años llevó una vida más bien lánguida; algún autor ha llamado al Convenio en su primera fase la «bella durmiente» ${ }^{11}$. Firmado el Convenio en 1950 , no entró en vigor hasta 1953, al obtenerse la décima ratificación; la Comisión Europea de Derechos Humanos no se creó hasta 1956, y el Tribunal Europeo hasta 1959, dictando su primera sentencia en 1960

9 Para un análisis, desde una perspectiva española, de lo que se supuso esta innovación, pueden consultarse los trabajos de dos jueces españoles del Tribunal de Estrasburgo: J.A. PASTOR RIDRUEJO, «El proceso de internacionalización de los derechos humanos: el fin del mito de la soberanía nacional»(I). Plano universal:la obra de las Naciones Unidas» y J.A. CARrillo SALCEDO: «El proceso de internacionalización de los derechos humanos: el fin del mito de la soberanía nacional (II). Plano regional: el sistema de protección instituido en el Convenio Europeo de Derechos Humanos", ambos en la obra Consolidación de derechos y garantías: los grandes retos de los derechos humanos en el siglo XXI, Madrid, Consejo General del Poder Judicial, 1999, pp. 35-46 y 47-76 respectivamente.

10 WILDHABER, loc, cit.

11 J. Frowein,»European Integration through Fundamental Rights», Michigan Journal of Law Reform, 18, 1984. cf. Bates, 11 
(Lawless contra Irlanda). Contrariamente a lo que quizás se había supuesto, no hubo muchas demandas interestatales en el primer decenio de vigencia del Convenio; para ser precisos, hubo tres, en los casos Grecia contra Reino Unido (dos demandas, en 1956 y 1957) y Austria contra Italia (1960). Tampoco fueron muy abundantes las demandas individuales presentadas ante la Comisión frente a los Estados que habían optado en favor de esta vía; y en la gran mayoría de los casos, fueron la Comisión o el Comité de Ministros los órganos encargados de resolver definitivamente esos casos. Hasta bien entrados los años sesenta, en muy pocas ocasiones se enviaron casos al Tribunal, bien por la Comisión (por ejemplo, la Comisión no envió ningún caso al Tribunal entre 1960 y 1965) bien por el Estado afectado.

Las grandes líneas inicialmente inspiradoras de la creación del Convenio se mostraron pues poco efectivas. En lo que se refiere a la garantía interestatal ante derivas totalitarias, la realidad europea mostró que esas derivas no eran muy probables, en la situación de congelación de bloques en los años cincuenta y sesenta; la función de integración europea se trasladó pronto a otros foros, como la Comunidad Europea del Carbón y el Acero y el Mercado Común; en cuanto a la garantía individual de derechos, la desconfianza mostrada por algunos Estados, la tardanza en la constitución del Tribunal, y las pocas adhesiones a esa vía no la hicieron inicialmente muy operativa.

Durante esta época (entre 1956 y 1975, podría decirse) el protagonismo dentro del sistema le correspondió sobre todo a la Comisión, quedando el Tribunal en un segundo lugar ${ }^{12}$. No obstante, se fue produciendo, muy lentamente, una evolución del sistema, que acabaría alterando las previsiones de sus creadores o al menos de muchos de ellos. El alcance de los derechos protegidos por el Convenio se amplió mediante varios Protocolos de reforma: así el Protocolo Adicional de 1952 (que garantizaba el derecho de posesión pacífica, el derecho de los padres a la forma de educación de sus hijos y el derecho a elecciones libres) y el Protocolo 4 en 1963. El número de ratificaciones del Convenio fue aumentando progresivamente durante los años sesenta y setenta, incluyendo a los antiguos regímenes dictatoriales del sur de Europa, y reintegrando a Grecia tras la caída del régimen de los coroneles. Igualmente, fue aumentando el número de países que aceptaban el recurso individual y la jurisdicción del Tribunal. A ello debe añadirse que la Comisión Europea de Derechos Humanos fue desarrollando una doctrina sobre la interpretación de esos derechos, que de alguna forma presagiaba un futuro desarrollo del sistema ${ }^{13}$.

\section{LA CONSOLIDACIÓN DEL TRIBUNAL COMO ÓRGANO ESENCIAL DE SISTEMA}

Todos estos factores fueron contribuyendo a que, por una parte, se reforzase el carácter del Convenio como Carta de Derechos europea, y por otra, y correlativamente, el eje de gravedad del sistema del Convenio se fuera desplazando progresivamente de la Comisión al

12 Ver sobre este tema, las observaciones de L. Wildhaber, Presidente del Tribunal entre 1998 y 2007, en «The Old Court, the New Court and Paul Mahoney», Human Rights Law Journal, 36, 2016, 292-297, p. 293. Para un análisis del papel de la Comisión, el artículo «clásico» es el de J. Frowein, «Die Rolle der Europäischen Menschenrechtskommission bei der Entwicklung der Europäischen Menschenrechtskonvention», en Europäische Grundrechtszeitschrift, 42, 2015, pp. 269-275.

13 Por ejemplo, ver los comentarios de BATES, op.cit. pp. 242 y ssgs. sobre el papel de la Comisión en el caso «East African Asians», 1973. 
Tribunal. El aumento de países firmantes del Convenio, y el correspondiente aumento de demandas individuales fueron dando oportunidad al Tribunal de elaborar una interpretación de los derechos del Convenio que implicaba una efectiva garantía de esos derechos, que tenía una cada vez mayor difusión en el mundo de los actores del Derecho, y que a su vez, daba lugar a una mayor afluencia de demandas. El profesor Ed Bates ${ }^{14}$, desde la perspectiva británica, coloca el punto de inflexión en el desarrollo del Convenio, confirmando la posición clave del Tribunal, en la sentencia Golder contra Reino Unido, de 1975. En esta sentencia, el Tribunal, frente a la opinión del juez británico, optó por una interpretación del derecho a un proceso equitativo, del artículo 6 del Convenio (en una aplicación innovadora de los términos de la Convención de Viena sobre la interpretación de los tratados) no meramente literalista, y restrictiva en favor de los Estados firmantes, sino claramente garantista y, desde una perspectiva actual, activista. Sea o no Golder el punto de inflexión, a partir de 1975 la actividad del Tribunal aumenta progresivamente, tanto en aspectos cuantitativos como cualitativos. Entre 1975 y 1979 dictó diecisiete sentencias sobre el fondo; en ellas fue afirmando las líneas básicas de su jurisprudencia, que se mantendrían hasta hoy. Así, en Tyrer contra Reino Unido, de 1978, la idea del Convenio como un «instrumento vivo»(living instrument) frente a interpretaciones «historicistas»; en Marckx contra Bélgica, de 1979, el concepto de »margen de apreciación»; en Airey contra Irlanda ( 1979) la afirmación de que el Convenio perseguía una protección real y efectiva, y no meramente formal de los derechos en él consagrados; en Engel contra Paises Bajos, de 1976, el Tribunal acuña la noción de «conceptos autónomos».

La posición del Tribunal y el papel del Convenio como Carta de Derechos, frente una interpretación del mismo como garantía antitotalitaria se vieron decisivamente reforzados tras la disolución del bloque de los países del centro y este de Europa dirigidos por la pronto extinta Unión Soviética. Los acontecimientos del año 1989 condujeron, en un corto plazo, a la aparición de numerosos regímenes constitucionales en ese área que pretendían, como muestra de homologación democrática, la inserción en el Consejo de Europa y la inclusión entre los países del Convenio; además, la necesidad de una garantía interestatal antitotalitaria desaparecía o se reducía considerablemente. En la nueva situación, algunas de las estructuras creadas en 1950 aparecían como innecesarias o al menos como disfuncionales, ante el incremento del número de demandas, y la necesidad de establecer unos standards mínimos sobre derechos humanos en el nuevo «orden público europeo». En palabras del Presidente Wildhaber, «muchos de los casos que llegaban a Estrasburgo tenían poco que ver con el objetivo inicialmente proclamado del Convenio esto es, la derrota de las dictaduras totalitarias» ${ }^{15}$.

\section{LAS REFORMAS DEL PROTOCOLO 11}

La evolución del sistema del Convenio, en sus aspectos cuantitativos y cualitativos llevó a una radical reforma mediante el Protocolo 11, que entró en vigor en 1998, y que vino a consolidar la dimensión del Convenio como instrumento de protección de derechos individuales. Se ha puesto en ocasiones el acento en los cambios que supuso la desaparición del enfrentamiento entre bloques propio de la guerra fría, y la incorporación de las nuevas

14 BATES, op. cit., pp. 290 y ss.

15 WildhaBer, «The Old Court...» cit. p. 294. 
democracias al sistema del Convenio; pero también por alguno de los protagonistas de la reforma ha podido afirmarse que ésta era ya previsible desde anteriormente, debido tanto al crecimiento de las demandas ante la Comisión como a la percepción de la situación de inferioridad procesal en que se encontraban los recurrentes individuales en comparación con los Estados ${ }^{16}$. Ya en 1985 el Gobierno suizo propuso fundir Comisión y Tribunal en un solo órgano, pero la propuesta encontró seria resistencia. No obstante (en parte por la acción del Presidente Ryssdal, y a sus instancias, del Gobierno noruego $)^{17}$ la reforma siguió su camino, y una conferencia interministerial encomendó al Consejo de Europa la elaboración de un proyecto de Protocolo, eventualmente ratificado por todos los países miembros y que modificaba sustancialmente los aspectos procedimentales del Convenio.

El Protocolo 11 supuso la consolidación del Convenio como carta de derechos individuales, y el protagonismo del Tribunal. La Comisión Europea desapareció, o mejor dicho, vino a fundirse con el Tribunal, dando lugar a lo que se llamó «el nuevo Tribunal» que asumía las funciones de los dos órganos: de hecho en el nuevo Tribunal se integraban miembros de los «antiguos» Tribunal y Comisión. El Tribunal se estructuraba como órgano permanente, integrado por jueces a tiempo completo, y se abría el acceso directo de los recurrentes al Tribunal, suprimiéndose el filtro que representaba la Comisión. El recurso individual, a partir de entonces, se configura como el elemento eje del sistema del Convenio. Las decisiones sobre la inadmisibilidad de las demandas se encomendaban como regla general a comités de tres jueces, y la resolución sobre el fondo a salas de siete jueces. Debido a las dudas de varios Estados sobre la conveniencia de que hubiera una única instancia, integrada por las salas, el Convenio introdujo una nueva composición, la Gran Sala del Tribunal, que podría conocer de casos provenientes de las salas, a petición de los Gobiernos o de las mismas salas del Tribunal.

Lo que podría llamarse «judicialización» del sistema se completaba mediante la reducción de las facultades del Comité de Ministros del Consejo de Europa; sus funciones se reducían a supervisar la ejecución de las sentencias del Tribunal. Debe tenerse en cuenta en todo caso que el papel del Comité seguía siendo muy destacado, en cuanto aseguraba que las sentencias en cuestión, aún «declarativas» en la forma, cobraban efectividad en los países afectados. Valga decir que la existencia del Comité de Ministros supone una diferencia considerable, en cuanto a la efectividad de la protección concedida por el sistema, respecto de otros casos, señaladamente el sistema interamericano de derechos humanos, en que no existe un órgano similar, y es el propio Tribunal Interamericano el que ha de velar por el cumplimiento de sus sentencias.

\section{LA EVOLUCIÓN DESDE EL PROTOCOLO 11. LA DIMENSIÓN CUANTITATIVA}

En forma no sorprendente, las innovaciones introducidas por el Protocolo 11, especialmente el acceso directo de los recurrentes al Tribunal supusieron un notable incremento

16 Tal es la opinión expresada por Morten RuUd, en «The Court: historical framework», en Conference on the long term future of the European Court of Human Rights, Estrasburgo, Consejo de Europa, 2014, pp. 23-27. RUUD fue el presidente del órgano (DH-PR) encargado de elaborar el proyecto de Protocolo.

17 Ver al respecto la intervención de Martin Krujuer, en Conference... cit. en nota anterior, pp. 33-38 
del ya considerable número de demandas. Hacia el año 2008, la media anual era de unas sesenta mil; ello supuso, a pesar del aumento de decisiones y sentencias por parte del Tribunal, que se fuera acumulando un considerable retraso. Hacia el año 2010, los casos atrasados llegaban a casi ciento sesenta mil. La gravedad de la situación dio lugar a que el Consejo de Europa nombrase una «Comisión de Sabios» presidida por el español Gil Carlos Rodríguez Iglesias, para proponer cambios y mejoras en el sistema.

Por su parte, el Tribunal llevó a cabo diversas reformas internas a efectos de incrementar su capacidad resolutiva; como ejemplo, reformó su Reglamento para establecer un sistema de prioridades, de manera que, en lugar de seguir un orden estrictamente cronológico de resolución, según la fecha de presentación de demandas, éstas se examinaran de acuerdo con la gravedad del tema que plantearan, estableciéndose diversas categorías. No obstante, y como es lógico, fueron los Estados parte del Convenio los que llevaron a cabo una actividad reformadora encaminada a resolver los graves problemas derivados de la acumulación de casos.

Esta actividad se tradujo esencialmente en la nueva reforma del Convenio llevada a cabo por el Protocolo 14, que entró en vigor (con algún retraso desde su aprobación, debido a la actitud reticente de la Federación Rusa) el año 2010.

El Protocolo 14 introdujo considerables cambios en el funcionamiento del Tribunal. En cuanto a su composición, el mandato de los jueces se extendía a nueve años (frente a seis en la regulación anterior) sin posibilidad de reelección. Pero las innovaciones más señaladas se referían a los órganos de funcionamiento del Tribunal. Se creaba una nueva formación de un solo juez, encargado como principio general, de decidir (en lugar, como anteriormente, de un comité de tres jueces) sobre la inadmisibilidad de las demandas presentadas; con la particularidad de que el juez no podía en ningún caso ser el elegido con respecto al país de origen de las demandas. Adicionalmente, se posibilitaba que los comités de tres jueces pudieran dictar sentencias sobre el fondo en casos de mera aplicación de la jurisprudencia del Tribunal. Como medida añadida, se preveía que el Comité de Ministros, a petición del Tribunal, pudiera reducir de siete a cinco el número de jueces integrantes de cada sala, amentando así el número de éstas (si bien hasta el momento no se ha hecho uso de esa posibilidad, manteniéndose el número de cinco salas). Finalmente, y respondiendo, como se verá, a una cierta tendencia hacia la «constitucionalización» del Tribunal, se estableció como causa de inadmisión de una demanda que el demandante no hubiera «sufrido un perjuicio importante» (artículo 35, 3 b) introduciéndose el principio «de minimis non curat praetor» ${ }^{18}$.

Los efectos del Protocolo $14 \mathrm{y}$ de las medidas racionalizadoras del trabajo introducidas por el Tribunal fueron destacados, reduciéndose notablemente el número de casos «embolsados». Valga decir que ello se debió en gran parte a la aplicación, por parte del Tribunal (siguiendo en esto una línea de conducta anterior) de estrictos criterios de admisibilidad; de hecho, los casos no rechazados por el Tribunal y comunicados a los correspondientes Gobiernos para la formulación de observaciones representan un muy pequeño porcentaje de las demandas presentadas, lo que no ha dejado de dar lugar a críticas. En todo caso, y como resulta de la literalidad del Convenio, el Tribunal no goza de discreción (como a veces se ha propuesto) para seleccionar las demandas que considere

18 Para un comentario sobre el (limitado) uso de esta cláusula por el Tribunal, ver G. CANO PALOMARES, «La existencia de un perjuicio importante como nueva condición de admisibilidad tras la entrada en vigor del protocolo num. 14 al CEDH», en Revista Española de Derecho Europeo, 42 (2012) 49-73. 
más relevantes, siguiendo un sistema similar a la concesión del writ of certiorari del Tribunal Supremo norteamericano, o, en expresión coloquial anglosajona, del «pick and choose». Los motivos de inadmisibilidad siguen siendo tasados, si bien se formulan en el Convenio con una cierta flexibilidad. Flexibilidad que se ve facilitada por la práctica del Tribunal de no motivar las decisiones de inadmisibilidad dictadas por el juez único, práctica ésta también sometida a críticas, y sujeta a revisión.

\section{LA DIMENSIÓN CUALITATIVA}

El aumento de países miembros del Convenio, la situación existente en muchos de esos países — particularmente, aunque no sólo, los integrantes del antiguo bloque del Este- y el correlativo incremento de las demandas presentadas al Tribunal, dieron la oportunidad a este de enfrentarse con una multiplicidad de problemas relativos al contenido y extensión de los derechos del Convenio que no se habían planteado en las fases anteriores; por otro lado, la ratificación y consiguiente entrada en vigor en la mayoría de los Estados de varios protocolos adicionales de reforma introdujeron nuevos derechos cuya protección le incumbía. El Tribunal, en estas ocasiones, puso en práctica los principios ya elaborados: el principio de la efectividad de los derechos proclamado en Airey, el de la consideración del Convenio como un instrumento vivo establecido en Tyrer, o la aplicación del concepto de obligaciones positivas acuñado en Marckx. Ello dio lugar a una jurisprudencia que supuso en algunos casos una interpretación novedosa (o al menos distinta de la tradicionalmente aceptada) de los derechos del Convenio, interpretación que, como se apuntará más abajo, fue en ocasiones considerada indebidamente expansiva $^{19}$. Así, el Tribunal pudo interpretar los artículos 2 y 3 del Convenio, sobre todo a partir de su sentencia McCann y otros c. Reino Unido (1995), en el sentido de que el respeto a la vida y la prohibición de torturas y tratos inhumanos o degradantes implicaba no solo obligaciones negativas de abstención de conductas atentatorias a tales derechos, sino también obligaciones positivas de investigación de alegaciones al respecto, con carácter pronto y, suficiente, y con participación de los afectados; pudo también aplicar su interpretación amplia del derecho a la vida privada y familiar del artículo 8 como extendido también a las relaciones sociales y —a partir sobre todo de Lopez Ostra contra España (1994) — a la vida familiar domiciliaria afectada por el medio ambiente o el ruido; y, sobre todo, llevó a cabo una interpretación del derecho a un proceso equitativo, del artículo 6, que cubría prácticamente todos los aspectos del proceso civil y penal, particularmente, como en Salduz c. Turquía (2009), en relación con la garantía que representa la asistencia letrada. Ciertamente, no se trataba, ni podía tratarse, de creación de nuevos derechos no incluidos en el Convenio y sus Protocolos, pero sí de una interpretación de los mismos que tenía en cuenta la evolución de los desafíos a los derechos humanos no sólo en sociedades recientemente llegadas a un régimen constitucional, sino también a sociedades de democracia consolidada pero sujetas a un continuo desarrollo; lo que por

19 La crítica «clásica» a esa tendencia expansiva de la jurisprudencia del Tribunal es la representada por la conferencia del juez británico Lord L. HofFmann The Universality of Human Rights, Judicial Studies Board Annual Lecture, 19 de marzo de 2009, https://www.judiciary.uklannouncements/speech-by-lord-hoffmann-the-universality-of-buman-rights Reproducida en Law Quarterly Review, 125, 2009, 416.

UNED. Teoría y Realidad Constitucional, núm. 42, 2018, pp. 111-130 
otra parte se facilitaba por el empleo por el Tribunal de los «conceptos autónomos» establecidos en su citada sentencia Engel.

Una exposición de las líneas jurisprudenciales con respecto al contenido sustantivo de los derechos del Convenio representaría una tarea muy superior a la que aquí se pretende realizar; pero sí resulta ilustrativa del desarrollo del papel del Tribunal una exposición de algunas interpretaciones de orden procesal, sobre el alcance de las funciones del Tribunal, que suponen sin duda una visión expansiva de las mismas. En las líneas que siguen se hará referencia a tres aspectos de esa interpretación: la extensión de la misma jurisdicción del Tribunal, la adopción de medidas cautelares y la inclusión de mandatos ejecutivos en la parte dispositiva de sus sentencias.

\section{VII.1. La ampliación de la jurisdicción territorial del Tribunal}

El artículo 1 del Convenio especifica que «las Altas Partes Contratantes reconocen a toda persona bajo su jurisdicción los derechos y libertades definidos en el Título I del presente Convenio». La determinación de cuál sea el ámbito de la jurisdicción de los Estados determinará pues la extensión territorial de la jurisdicción del Tribunal, en el sentido de que ésta no alcanzará ámbitos territoriales fuera de la jurisdicción de los Estados miembros del Convenio.

En un primer momento, y como se apuntó, la presencia de posesiones coloniales de los Estados firmantes no dejó de influir en los términos del Convenio; en este una «cláusula colonial» (art. 56) venía a precisar su posible aplicación en los territorios «de cuyas relaciones internacionales (sea) responsable» el Estado miembro. El artículo 4 del Protocolo Adicional realizó una referencia similar respecto de sus disposiciones.

La cuestión se plantea en forma distinta en la actualidad, y se refiere sobre todo a las obligaciones de los Estados derivadas del Convenio en actuaciones, sobre todo de tipo militar, fuera de sus fronteras. Este tipo de actuaciones por parte de Estados miembros del Convenio se ha hecho relativamente frecuente, en el marco de misiones auspiciadas por organizaciones internacionales. En este aspecto, es visible una cierta evolución de la jurisprudencia del Tribunal en lo que se refiere al concepto de «jurisdicción» estatal, evolución que ha conducido a una extensión de la jurisdicción propia del Tribunal ${ }^{20}$.

Esta evolución a lo largo de la actual fase del Tribunal se muestra, por ejemplo, si se comparan resoluciones recientes con su posición inicial, representada, entre otras, por el caso Bankovic (2001). La demanda se refería al bombardeo por aviones de la OTAN, integrados en las fuerzas armadas de Estados miembros del Convenio, de una estación de televisión de Yugoslavia. En su decisión de inadmisión, el Tribunal admitió que pudiera haber casos en que la jurisdicción estatal se extendiera a lugares fuera de su ámbito de soberanía, pero que en general, la jurisdicción estatal estaba limitada por los derechos de soberanía territorial de los demás Estados. La existencia de una jurisdicción extraterritorial era pues excepcional y había que analizarla caso por caso. En el supuesto planteado en Bankovic, el Tribunal resolvió que habiendo sucedido los hechos en el espacio

20 Sobre esta cuestión puede hallarse un profundo análisis en el artículo de la juez A. NussBerger «The Concept of 'Jurisdiction' in the Jurisprudence of the European Court of Human Rights, Current Legal Problems, 65, 2012, pp. 241-268. 
territorial de Yugoslavia, país no incluido en el espacio legal del Convenio, no existía un vínculo jurisdiccional entre las víctimas del bombardeo y los Estados demandados que justificara una decisión sobre la alegada violación.

Una decisión de inadmisibilidad por falta de jurisdicción territorial recayó en el caso Bebrami y Bebrami contra Francia (2007), esta vez relativo a la actuación de Francia en el marco de la fuerza internacional de seguridad en Kosovo establecida por el mandato de la resolución 1244 del Consejo de Seguridad de las Naciones Unidas. El Tribunal concluyó que esa fuerza internacional dependía de las Naciones Unidas, ente con personalidad distinta de los Estados miembros, y que no era parte del Convenio Europeo, por lo que la demanda contra Francia era inadmisible.

Esta posición de relativa autocontención se vio alterada por varias resoluciones posteriores del Tribunal, a partir de la sentencia en el caso Al Skeini y otros contra Reino Unido (2011) y diversas sentencias posteriores. En Al Skeini la cuestión se refería a la muerte de varias personas en la zona de Irak ocupada por las fuerzas militares británicas. El Tribunal resolvió que entre los supuestos excepcionales de extensión extraterritorial de la jurisdicción de un Estado se situaba el de que ese Estado ejerciera funciones públicas sobre un territorio fuera de su soberanía, y que esas funciones supusieran control y autoridad sobre las personas. En el caso, en las condiciones de ocupación de Irak, sí existía un vinculo jurisdiccional entre el Reino Unido y las víctimas de al actuación de las tropas británicas.

Esta posición se mantuvo por el Tribunal en los siguientes casos Al Jedda contra Reino Unido (2011), Hassan contra Reino Unido (2014) y Jaloud contra Paises Bajos (2014). En todos estos casos, la autoridades de Estados miembros del Convenio habían mantenido el mando sobre la actuación de sus fuerzas militares operando en Irak, que a su vez habían actuado en relaciones de control y autoridad sobre las personas que habían sido alegadamente víctimas de violaciones de derechos recogidos en el Convenio. El Tribunal, pues, reconoció la existencia de una jurisdicción extraterritorial de los Estados demandados, y en consecuencia, de su propia jurisdicción para decidir sobre las demandas presentadas.

\section{VII.2. Una cuestión compleja: la adopción de medidas provisionales}

El Tribunal ha insistido en numerosas ocasiones ${ }^{21}$ en que la protección que presta frente a violaciones de los derechos reconocidos en el Convenio ha de ser efectiva, y no meramente formal o ilusoria. Una de las cuestiones que plantea esta posición es la referida a la posible adopción de medidas provisionales, antes de que se produzca la decisión sobre el fondo de un determinado caso. En efecto, en muchos supuestos, la dilación en la adopción de una decisión puede suponer que la violación del derecho que se pretende vulnerado sea ya irreversible e irremediable.

En el Convenio Europeo no se hace referencia a ningún tipo de medidas cautelares. Sin embargo, como es evidente, la efectividad de la tutela a prestar por el Tribunal Europeo depende en muchos supuestos de la aplicación de este tipo de medidas. El ejemplo más típico es el consistente en demandas de personas que van a ser extraditadas o

21 Desde la citada sentencia en Airey c. Irlanda, de 9 de octubre de 1979. 
expulsadas a un país en que corren serio riesgo de verse sometidas a penas o tratos incompatibles con el Convenio. De acuerdo con la jurisprudencia del Tribunal, el deber de los Estados firmantes se extiende a proteger a las personas sujetas a su jurisdicción frente a penas o tratos contrarios a los artículos 2 y 3 del Convenio, lo que comprende la prohibición de deportarlos a países donde corran grave riesgo de verse sometidos a esos tratos ${ }^{22}$.

Ahora bien, planteada una demanda ante el Tribunal Europeo de Derechos Humanos frente a una orden de expulsión o deportación en tales circunstancias, se corre el grave riesgo de que, si se lleva a cabo efectivamente, la eventual resolución del Tribunal sea tardía e inútil, si el demandante ya hubiera sido deportado al país de que se trate. Ello explica que, ante el silencio del Convenio, el Reglamento interno del Tribunal (Rules of Court) haya previsto la adopción de estas medidas cautelares o provisionales en su artículo 39, que dispone en su apartado 1 que «la Sala, o en su caso su presidente, podrá, a instancia de parte de o de cualquier otra persona interesada, o de oficio, indicar a las partes cualquier medida cautelar que estime necesaria en interés de las partes o del buen desarrollo del proceso».

La aplicación de este precepto se está haciendo cada vez más frecuente, sobre todo (aunque no solo) en los supuestos citados de deportación o expulsión, cuando se han invocado como (eventualmente) vulnerados los artículos 2 y 3 del Convenio. El texto del Reglamento se refiere sólo a que el Tribunal podrá «indicar» que estima necesaria la adopción de una medida provisional, sin que se haga referencia al carácter obligatorio de esa adopción. Ahora bien, la evolución de la jurisprudencia del Tribunal (a la vista de la práctica de otros Tribunales internacionales) ha conducido a establecer el carácter vinculante y no meramente indicativo de la adopción de esa medida. Efectivamente, y frente a precedentes iniciales en otro sentido (así, en el caso Cruz Varas c. Suecia ${ }^{23}$, relativo a la fuerza vinculante de medidas adoptadas por la Comisión) el Tribunal, en forma consistente, ha considerado que el no seguimiento por parte del Estado demandado de sus indicaciones referentes a la adopción de medidas provisionales constituye una violación del artículo 34 del Convenio, según el cual, por un lado, se reconoce el derecho al acceso al Tribunal, y por otro se establece que los Estados firmantes «se comprometen a no poner traba alguna al ejercicio eficaz de este derecho».

Así, en el caso Mamatkulov y Askarov c. Turquía ${ }^{24}$ el Tribunal estimó que se había producido la violación del artículo 34 del Convenio debido a que, pese a la indicación en contra del Tribunal en aplicación del artículo 39.1 del Reglamento, el gobierno turco había procedido a extraditar a Uzbekistán a varias personas que habían presentado una demanda ante el peligro de verse allí sometidas a malos tratos. Posteriormente, en el caso Paladi c. Moldova ${ }^{25}$ el Tribunal aplicó de nuevo esta doctrina, si bien en relación con un supuesto distinto al de la extradición. En Paladi una Sala del Tribunal procedió a aplicar el artículo 39 del Reglamento ordenando al gobierno moldavo que mantuviera al demandante en un centro médico especializado, a la vista del peligro que corría su salud si se le trasladaba a un centro ordinario de detención. No habiendo atendido el gobierno ese requerimiento, la Sala estimó que se había producido una vulneración del artículo 34, lo que fue confirmado por una sentencia posterior de la Gran Sala. En forma consistente, el

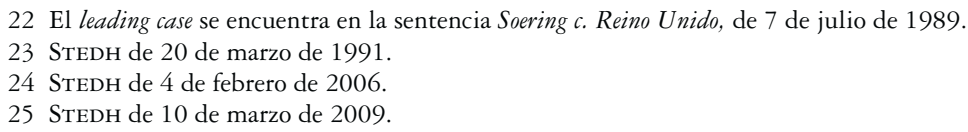


Tribunal ha considerado que la violación del artículo 34 caso de no adopción de las medidas provisionales indicada es independiente de que se materialice o no el riesgo que llevó a su adopción ${ }^{26}$. Tampoco ha admitido que, una vez indicadas tales medidas, en el supuesto de expulsión a un país en que el recurrente corre riesgo de malos tratos, el Gobierno del Estado expulsor no las aplique por haber recibido seguridades diplomáticas por parte del país destinatario ${ }^{27}$

\section{VII.3. Mandatos ejecutivos en las sentencias del Tribunal}

Como otra muestra de la evolución de la jurisprudencia del Tribunal adoptando remedios procesales no explícitamente previstos en las disposiciones del Convenio, en una interpretación expansiva del mismo, en ciertos casos, el Tribunal, junto a la declaración de una violación del Convenio y eventualmente, del otorgamiento de una satisfacción equitativa, procede a dictar en su fallo las medidas específicas en el caso individual, que deben adoptarse en ejecución de sus sentencias, indicando que se trata de medidas obligatorias. Desde su sentencia en 2004 en el caso Assanidze contra Georgia, muchas sentencias del Tribunal han ido más allá de la declaración de una violación del Convenio y la concesión de una satisfacción equitativa, para incluir otros mandatos directos a los Estados, con un estilo claramente imperativo. En Assanidze, el Tribunal decidió por unanimidad que «el Estado demandado debe asegurar la liberación del recurrente lo antes posible». Y mandatos similares pueden encontrarse en sentencias posteriores, como las recaídas en los casos Ilascu contra Moldavia y Rusia (2004), Gladysheva contra Rusia (2011), Oleksandr Volkov contra Ucrania (2013), o Glubacovic contra Croacia (2011).

En este último caso, como ejemplo de otros pronunciamientos vinculantes, valga señalar que, en aplicación del artículo 46 el Tribunal precisó la medida concreta a adoptar en materia de relaciones familiares, declarando que «teniendo en cuenta las circunstancias particulares del caso, y la urgente necesidad de poner fin a la violación del artículo 8 del Convenio, el Tribunal considera que, para cumplir con su obligación derivada del artículo 46 del Convenio, el Estado demandado deberá asegurar el contacto efectivo entre el recurrente y su bija, en un momento que sea compatible con el horario laboral del demandante, y en adecuadas circunstancias, sobre la base de la sentencia del Tribunal Municipal de Rijeka de 8 de marzo de 2010». De la misma manera, y con una fórmula similar, en la sentencia en el caso MSS contra Bélgica y Grecia (2011) el Tribunal ordenó al Gobierno griego que se abstuviera de deportar al recurrente en tanto se tramitaba su petición de asilo. Una decisión del mismo tipo puede encontrarse en la sentencia del año 2014, A.C. y otros contra España.

También con respecto a España, en el caso Del Río Prada contra España (2013), el Tribunal dictó un mandato de liberación de la recurrente, indicando que «teniendo en cuenta las particulares circunstancias del caso y la urgente necesidad de poner fin a las violaciones del Convenio que ha verificado, considera que es deber del Estado demandado asegurar que la demandante sea puesta en libertad lo antes posible». Debe señalarse que la sentencia se hizo pública el 21 de octubre de 2013: al día siguiente la demandante fue puesta en libertad en virtud de una decisión unánime del plenario de la Sala de lo Penal de la Audiencia

26 STEDH Olaechea Cahuas c. España, de 10 de agosto de 2006.

27 STedH Ben Khemais c. Italia, de 24 de febrero de 2009.

UNED. Teoría y Realidad Constitucional, núm. 42, 2018, pp. 111-130 
Nacional. En su reunión de 5 de diciembre del mismo año, el Comité de Ministros del Consejo de Europa «tomó nota de que la demandante fue puesta en libertad el 22 de octubre de 2013 tras una decisión de la Audiencia Nacional, y da la bienvenida la respuesta dada a la medida urgente individual indicada por el Tribunal Europeo».

\section{VIII. ¿EL TRIBUNAL EUROPEO COMO JURISDICCIÓN «CUASI CONSTITUCIONAL»?}

Si en una fase inicial, como se ha visto, el Convenio Europeo pretendió centrar sus previsiones básicamente en una garantía interestatal contra el totalitarismo, y en una fase posterior vino a mostrarse como un sistema de garantía de derechos individuales, no faltan indicios de que en los momentos actuales va adquiriendo una dimensión adicional, la de «instrumento constitucional del orden público europeo», en términos de la sentencia en el caso Loizidou contra Turquía del año 1996, que implica una cierta proyección normativa de las decisiones del Tribunal. En efecto, si el artículo 46.1 del Convenio se refiere a la obligación de los Estados de acatar las decisiones del Tribunal «en los litigios en que sean parte», la experiencia ha demostrado que los efectos de las sentencias tienen también un alcance general. A la luz de la jurisprudencia de Estrasburgo, y de la práctica de los Estados del Convenio, la obligación de cumplir las sentencias del Tribunal se ha entendido como incluyendo la obligación de prevenir futuras y similares violaciones ${ }^{28}$. De acuerdo con el principio de res interpretata, proclamado en el artículo 32.1 del Convenio ${ }^{29}$, las sentencias de Estrasburgo no se limitan a resolver el caso específico planteado ante el Tribunal, sino que también establecen pautas para la interpretación de los mandatos del Convenio en casos futuros. Ello tiene importantes consecuencias sobre el ordenamiento jurídico de los Estados miembros, bien afectando la interpretación por los tribunales nacionales del Derecho existente, bien dando lugar a reformas y cambios de las leyes en vigor. Ha de señalarse que, con independencia de cualquier pronunciamiento sobre el tema por parte del Tribunal de Estrasburgo, en no pocas ocasiones los tribunales de algunos Estados ya habían tomado tempranamente la iniciativa a la hora de extender los efectos de las sentencias del Tribunal en su labor de reinterpretación de las normas domésticas.. Valga recordar los cambios efectuados por tribunales nacionales en la interpretación del Derecho vigente, para acomodarlo a la jurisprudencia de Estrasburgo, tal como fue el caso en Bélgica y Austria tras las sentencias en Piersack (1982) y Unterpertinger (1986) respectivamente.

A raíz de los problemas derivados de la creciente carga de trabajo del Tribunal debidos al aumento de las demandas ante él presentadas, una de las soluciones propuestas fue la de convertir en la práctica al Tribunal de Estrasburgo en un Tribunal constitucional europeo, encargado de emitir directrices generales sobre temas de amplio alcance; la traducción procesal de esta solución sería la introducción de un sistema similar al certiorari

28 Por ejemplo en la Recomendación del Comité de Ministros Rec (2008)2, en que recuerda que las sentencias declarativas de una violación del Convenio imponen la obligación de « adoptar, cuando sea apropiado, las medidas generales necesarias para poner fin a tales violaciones o evitarlas en el futuro».

29 Art. 32.1, «La competencia del Tribunal se extiende a todos los asuntos relativos a la interpretación y aplicación del Convenio y de sus Protocolos que le sean sometidos en las condiciones previstas por los artículos 33,34, 46 y 47 ». 
norteamericano para seleccionar con amplia discrecionalidad los casos a resolver. Tuvo especial resonancia en este aspecto la posición favorable del anterior Presidente del Tribunal, Luzius Wildhaber ${ }^{30}$. Como se ha visto, no fue esta la solución adoptada, prefiriéndose la adopción de las fórmulas de agilización del procedimiento previstas en el Protocolo 14. No obstante, no puede ya negarse que son visibles tendencias dentro de la práctica del Tribunal (y en los instrumentos normativos que lo regulan) hacia el fortalecimiento de esa dimensión constitucional del Tribunal, con funciones más allá de la resolución de demandas individuales concretas relativas a la violación de los derechos del Convenio. Ya se ha hecho mención de la introducción del principio de minimis por el Protocolo 14. Si bien el Tribunal ha hecho un uso restringido de ese principio, no faltan indicios de que ciertamente existe una voluntad, tanto por parte de los Estados miembros como del mismo Tribunal, de reforzar esa dimensión cuasi-constitucional. Ejemplo de la posición del Tribunal a este respecto sería su utilización del artículo 46 del Convenio ${ }^{31}$; ejemplo de la posición de los Estados sería la introducción, en el Protocolo 16, recientemente entrado en vigor, de la vía de la opinión consultiva.

Con respecto a la actuación del Tribunal en lo que se refiere a la aplicación del artículo 46, cabe destacar que, aparte de los efectos generales que los tribunales de los Estados miembros han atribuido por iniciativa propia a las sentencias de Estrasburgo, el Tribunal también ha procedido, en los últimos años, a indicar medidas generales (usualmente de naturaleza legislativa) que los Estados deben adoptar para el cumplimiento de sus sentencias. Ello se lleva a cabo en dos formas: una que podría calificarse de tipo «suave», consistente en exhortar a los Estados a que lleven a cabo esas medidas generales, y otra, de tipo fuerte, mediante las llamadas «sentencias piloto»: pero debe señalarse ya que éstas representan sólo una de las formas posibles adoptadas por el Tribunal para señalar aquellas medidas generales a adoptar por los Estados ${ }^{32}$.

\section{VIII.1. Instrucciones de tipo general}

En cuanto al modelo «suave», un método empleado frecuentemente consiste en simplemente expresar en los fundamentos jurídicos de la sentencia la necesidad de que los Estados adopten medidas generales para remediar una violación del Convenio. En algunos casos, a la hora de señalar tales medidas a adoptar, los términos del Tribunal se producen en forma muy abierta. Por ejemplo, en Laska y Lika contra Albania (2010), en referencia a la reapertura de procedimientos conclusos para obtener una restitutio in

30 Ver por ejemplo, L. Wildhaber, «Rethinking the European Court of Human Rights» en J. ChristoFFERSEN y M. R. MAdSEN eds., The European Court of Human Rights between Law and Politics, Oxford, Oxford University Press, 2011, pp. 204230.

31 Artículo 46, 1 y 2: 1. Las Altas Partes Contratantes se comprometen a acatar las sentencias definitivas del Tribunal en los litigios en que sean partes. 2. La sentencia definitiva del Tribunal será transmitida al Comité de Ministros, que velará por su ejecución.

32 Me remito sobre este tema a las consideraciones efectuadas en dos trabajos previos del autor de estas líneas:»Compliance with Strasbourg Court Rulings: A General Overview» en K. Ziegler et. al. (eds.) The UK and European Human Rights: A Strained Relationship?, Oxford, Hart, 2015, pp. 323-340 y «Los derechos humanos como derechos efectivos: la evolución de la jurisprudencia del Tribunal Europeo de Derechos Humanos sobre ejecución de sentencias» en Derecho Constitucional Contemporáneo. Homenaje al Profesor Rubén Hernández Valle. San José de Costa Rica, Investigaciones Jurídicas S.A., 2015, pp. 437-451. 
integrum, el Tribunal empleó en los fundamentos jurídicos de la sentencia términos de naturaleza muy genérica, dejando al Estado un margen de discreción: «El Tribunal toma nota de que el sistema jurídico en materia penal del Estado demandado no ofrece la posibilidad de un reexamen de casos, incluyendo la reapertura de procedimientos internos en el caso de que este Tribunal haya encontrado la presencia de una violación grave del derecho del recurrente a un proceso equitativo...(...). Por otro lado, los Estados miembros tienen el deber de organizar sus sistemas judiciales de manera que sus tribunales puedan cumplir con las exigencias derivadas del Convenio. Este principio se aplica también a la reapertura de procedimientos y al reexamen del caso del demandante.»

Sin embargo, en otras ocasiones, el Tribunal es más preciso. Por ejemplo, en aplicación del art. 46 del Convenio, en el caso Gözel y Oser contra Turquía (2010), en que el Tribunal declaró la vulneración de derecho a la libertad de expresión, por la aplicación de un determinado artículo de la ley turca 3673, el Tribunal dispuso que «la violación, en el caso de los recurrentes, del derecho reconocido por el artículo 10 del Convenio deriva de un problema planteado por la redacción e interpretación de ese artículo». Como resultado, el Tribunal consideró que «una forma adecuada de reparación, que pondría fin a la violación declarada, podría ser el poner en concordancia el Derecho interno con el citado artículo del Convenio».

En este caso, el Tribunal proponía reformar el texto de un artículo específico de una ley concreta, a efectos de proporcionar una reparación adecuada a una vulneración del Convenio. En otro ejemplo, en Klaus y otros contra Georgia (2010) el Tribunal consideró que la violación del artículo 1 del Protocolo 1 era resultado de las deficiencias presentes en el ordenamiento jurídico de Georgia. En sus fundamentos jurídicos, la sentencia del Tribunal no sólo establecía que, para su ejecución, era necesaria la adopción, en el caso de Georgia, de medidas de tipo general, sino también que debían adoptarse urgentemente medidas de ese tipo en los ámbitos legislativo, administrativo y financiero, a efectos de permitir a los recurrentes el efectivo ejercicio de los derechos reconocidos en el Convenio (\$85). Pero, además, en el fallo, el Tribunal dispuso que si no se adoptaban tales medidas, el Estado demandado debería pagar a los recurrentes una compensación económica.

Este enfoque es ya común en la jurisprudencia del Tribunal. Cuando los mandatos del Tribunal se incluyen en el fallo de la sentencia, la fórmula es cercana (aunque no idéntica) a la de las sentencias piloto. Un ejemplo inicial puede encontrarse en Lukenda contra Eslovenia (2005) donde el fallo establece que las violaciones de los artículos 6.2 y 13 del Convenio declaradas en la sentencia derivaban del mal funcionamiento de la legislación doméstica, y que el Estado demandado debería garantizar el derecho a un juicio en tiempo razonable, a través de las medidas legislativas y la práctica adecuadas.

\section{VIII.2. Sentencias piloto}

En este contexto, la adopción del mecanismo de las sentencias piloto no representa un evento extraordinario en la jurisprudencia del Tribunal, sino más bien el empleo de un medio adecuado para dar efectos generales a sus sentencias cuando el número de casos repetitivos con que se enfrenta el Tribunal muestra que existe un defecto sistémico en el ordenamiento jurídico del Estado condenado. En estas sentencias, el Tribunal, tras constatar la existencia de ese fallo sistémico, y declarar la vulneración por el Estado de un derecho del Convenio, dicta instrucciones al Estado 
responsable de la vulneración, con respecto a los cambios que debe efectuar en su ordenamiento para ponerlo en concordancia con los mandatos del Convenio. Estas instrucciones (con un grado variable de precisión) se incluyen en el fallo de las sentencias, en donde también suele precisarse un plazo para el cumplimiento de las propuestas del Tribunal. Este plazo puede variar desde seis (Olaru y otros contra Moldavia, 2009) a dieciocho meses (Maria Atanasiu contra. Rumanía, 2010). En el caso Greens y M.T. contra Reino Unido (2011), la sentencia indicaba que el Estado demandado debía «a) presentar, dentro del plazo de seis meses desde que esta sentencia se convierte en definitiva, propuesta legislativas destinadas a reformar la Ley de 1983, así como, si fuera necesario, la ley de 2002 de forma que se adecuen al Convenio: y b) promulgar la legislación necesaria dentro del plazo que sea determinado por el Comité de Ministros». En todo caso, no es infrecuente que el Tribunal extienda los plazos concedidos a los Estados demandados. A la vista de lo expuesto anteriormente, cabe concluir que la aplicación de la técnica de las sentencias piloto no constituye un evento atípico en la jurisprudencia del Tribunal, sino que representa un grado más en el proceso de intervención del Tribunal en la ejecución de sus sentencias, apartándose del concepto clásico de sentencias puramente «declarativas» ${ }^{33}$.

Posiblemente en esta línea de constitucionalización del Tribunal pudiera incluirse su posición en el caso Burmych contra Ucrania, del año 2017. En el caso, las instrucciones dadas a Ucrania mediante una sentencia piloto no habían resultado en una actividad del Estado ucraniano remediando un fallo de tipo sistémico, que conducía a una general inejecución de sentencias dictadas por los Tribunales domésticos. La consecuencia fue la afluencia al Tribunal de miles de demandas de tipo repetitivo, idénticas a las que habían dado lugar a la sentencia piloto original. El Tribunal, ante esta situación, estimó que ya había cumplido su función, determinando las obligaciones del Estado ucraniano, careciendo de sentido la tramitación de esos miles de casos adicionales. En consecuencia, procedió a remitir al Comité de Ministros del Consejo de Europa, encargado de la supervisión del cumplimiento de las sentencias del Tribunal, esa serie de casos, para que adoptase las medidas necesarias.

\section{VIII.3. La opinión consultiva: el Protocolo 16}

No es sólo la jurisprudencia del Tribunal la que pone progresivamente el acento en los efectos generales de sus sentencias, y su proyección más allá del caso concreto, para informar los ordenamientos de los Estados miembros, al menos en cuanto al establecimiento de un standard mínimo de respeto de los derechos del Convenio. Son también los Estados miembros del Convenio los que, al introducir reformas al mismo vienen a subrayar progresivamente este aspecto. Muestra de ello pudiera ser la apertura a la ratificación del Protocolo 16 al Convenio, Protocolo que, al haber alcanzado las diez ratificaciones, entró en vigor para los Estados que lo hubieran ratificado el 1 de agosto de 2018. Este Protocolo establece la posibilidad de que los más altos órganos judiciales de los Estados pidan al Tribunal, con ocasión de litigios planteados ante

33 El artículo 61 del Reglamento del Tribunal precisa la tramitación de estas sentencias. Ver sobre este tema J. Abrisketa Uriarte, «Las sentencias piloto: el Tribunal Europeo de Derechos Humanos, de juez a legislador», en Revista Española de Derecho Internacional, 65, 2013, pp. 783-99 
ellos, una opinión consultiva sobre la interpretación que debe darse a un mandato del Convenio. La fórmula tiene alguna similitud con la cuestión prejudicial prevista en el artículo 246 del TFUE, pero muestra también al respecto notables diferencias; sólo, podrá plantearse por los altos órganos designados por cada Estado (y no por cada juez con ocasión de casos concretos ante él, como en el supuestos de la cuestión prejudicial) y se trata además de una opinión consultiva, esto es (teóricamente) no vinculante. No obstante, es evidente que, en el supuesto de que se haga uso de esta vía, sus resultados serán forzosamente apreciaciones de carácter general, dotadas de la fuerza interpretativa derivada de los mandatos del artículo 32.1 del Convenio; y ello no sólo respecto de los Estado u órganos que soliciten la opinión. Aún es pronto para verificar los efectos de esta reforma; no han faltado dudas sobre la eficacia de esta nueva vía para reducir la carga de trabajo del Tribunal o para fomentar el diálogo entre el Tribunal de Estrasburgo y los tribunales nacionales, y el autor de estas líneas ha tenido alguna oportunidad de expresarlas ${ }^{34}$. En todo caso, se trata de una manifestación de la tendencia apuntada hacia una «constitucionalización» del Tribunal.

\section{ESTADOS Y TRIBUNAL ANTE LA EVOLUCIÓN DEL CONVENIO}

Los cambios producidos entre su entrada en vigor y el momento actual han afectado, como se ha visto, a las mismas funciones del Convenio (de garantía interestatal frente al totalitarismo a Carta de derechos individuales y, al menos inicialmente, a «instrumento constitucional») y a la extensión e intensidad de la acción del Tribunal de Estrasburgo. Este desarrollo ha dado lugar, según se ha señalado, a problemas que han debido ser enfrentados, no sólo por los órganos del Convenio (Tribunal y Comité de Ministros) sino por los Estados integrantes del mismo, como últimos responsables y destinatarios de sus mandatos. La reacción de estos Estados miembros, y las medidas adoptadas conjuntamente han representado, en el último decenio, un elemento determinante en la evolución del sistema. Y ello tanto en lo que se refiere a las cuestiones de orden cuantitativo (número de demandas, retrasos en su resolución) como cualitativos (extensión e intensidad de la jurisdicción del Tribunal).

Los desafíos derivados de la puesta en práctica del Protocolo 11 dieron lugar a la celebración de una serie de conferencias internacionales de países del Convenio para hallar soluciones a los, problemas planteados al Tribunal; la conferencia inicial (en gran parte a iniciativa del entonces Presidente del Tribunal, Jean-Paul Costa) se celebró en Interlaken el año 2010, y posteriormente, se celebraron Conferencias en Izmir (2011) Brighton (2012) Bruselas (2015) y Copenhague (2018). De ellas, dos revisten una mayor relevancia; en lo que se refiere a los problemas de tipo cuantitativo del Tribunal, la Conferencia de Brighton supuso el establecimiento de una serie de criterios, relativos al ritmo de resolución de casos (las llamadas reglas de Brighton), determinando objetivos a lograr por el Tribunal en cuanto a plazos de resolución y supresión de pendencia. En lo que se refiere a los aspectos relativos a la jurisdicción del Tribunal, la Conferencia de

34 L. Lopez Guerra, «Le protocole n. ${ }^{\circ}$ 16: une vraie-fausse solution? Un début de réponse» en L. BurGoGUe-LaRsen, Les défis de l'nterpretation et de l'application des droits de l'bomme. De la ouverture au dialogue, Paris, Editions A. Pedone, 2017, pp. 365-370. 
Bruselas dio lugar a la redacción (además del ya citado Protocolo 16) del Protocolo 15 ( aún no entrado en vigor) que, aparte de reformas de tipo técnico sobre cuestiones de procedimiento, hizo referencia expresa, mediante una reforma del Preámbulo del Convenio, a dos cuestiones, ampliamente tratadas tanto en la jurisprudencia del Tribunal como en los trabajos académicos: el margen de apreciación de los Estados y el principio de subsidiariedad de la actuación del Tribunal respecto de los Estados.

Ambas cuestiones reflejan una creciente preocupación respecto de los límites de la jurisdicción del Tribunal. La primera versa sobre el ámbito de los Estados para adaptar a sus circunstancias propias los mandatos del Convenio, en su aplicación a casos concretos, habida cuenta de la inmediación con que sus autoridades actúan en relación con los hechos de casa caso; la doctrina del Tribunal ha reconocido reiteradamente la existencia de ese margen de aplicación, si bien dejando claro en todo momento que ello no suprimía la capacidad del Tribunal para decidir sobre la aplicación del Convenio. Por lo que se refiere al principio de subsidiariedad, esto es, que corresponde a los Estados poner en práctica los mandatos del Convenio, y que la acción del Tribunal sólo procede en defecto de acción efectiva estatal al respecto, y en todo caso sólo una vez agotados los recursos y remedios internos, se acepta comúnmente que tiene dos vertientes; por una lado supone una limitación a la acción del Tribunal, que se concibe como remedial o subsidiaria, y por otra una obligación de los Estados de poner en marcha mecanismos efectivos de protección de esos derechos.

El Protocolo 15 introduce una variación del Preámbulo al Convenio que menciona los dos temas: «Afirmando que las Altas Partes Contratatantes, de acuerdo con el principio de subsidiaridad tienen primariamenete la responsabiliodad de asegurar los derechos y libertades definidos en este Convenio y sus protocolos y que al hacerlo así disponen de un margen de apreciación, sujeto a la jurisdicción supervisora del Tribunal Europeo de Derechos Humanos establecido por este Convenio».

Esta fórmula aparece, por un lado, como reafirmación de líneas preexistentes en la jurisprudencia del Tribunal, pero, por otro, y en cuanto plasmación formal de esas líneas, como expresión de la preocupación de los Estados por establecer con claridad la delimitación de las respectivas esferas de la jurisdicción de Tribunal de Estrasburgo y de las autoridades estatales, sobre todo tras la discusión suscitada por diversas resoluciones contestadas (sobre todo en el ámbito académico, pero también en instancias oficiales) desde la perspectiva estatal ${ }^{35}$.

La ordenación de la compleja interrelación entre autoridades estatales y el Tribunal de Estrasburgo ha adquirido una nueva dimensión tras la aprobación del Tratado de Lisboa en 2009, y la previsión en él incluida de que la Unión Europea se adheriría al Convenio Europeo de Derechos Humanos. Con ello se ha venido a añadir un elemento más a lo que ha podido denominarse la «superpoblación» (overcrowding) ${ }^{36}$ de niveles de protección de derechos humanos en Europa: los niveles nacionales ( protagonizados por los

35 Valgan como ejemplo de esta preocupación las reacciones, tanto en la doctrina como en sede parlamentaria en el Reino Unido frente a la sentencia en el caso Hirst c. Reino Unido, del año 2005; o, más recientemente, la reacción (esta vez en sede legislativa) en la Federación Rusa, respecto de la sentencia Anchugov y Gadkov contra Rusia, del año 2013.

36 Utilizo el término empleado por Pedro Cruz Villalon, en Human Rights in Europe: the Crowded House, Londres, King's College London, Working Papers on European Law, Working Paper 61/2012. 
tribunales supremos y constitucionales de los Estados) el nivel del Convenio y, tras 2009, el derivado de la Carta de Niza y su protección por el Tribunal de Justicia. Cabe esperar que, como en el pasado, el sistema del Convenio sepa adaptarse a las nuevas necesidades de una sociedad europea cada vez más compleja.

Title: The evolution of the European system of protection of buman rights

Abstract: The European system of protection of human rights created by the European Convention of 1950 bas been subject of a deep evolution since its creation, concerning both its extension and its goals and proceedings. Three phases aat least are visible in this evolution: a first phase, initially oriented to an inter-State collaboration, where the main role corresponded to the European Comission of Human Rights; a second phase, centered on the individualised protection of Convention rights by the European Court of Humna Rights; and finally, ir seems that a third phase is starting, in which the Strasbourg Court is assuming a quasi-constitutional function.

Resumen: El sistema europeo de protección de derechos humanos resultante del Convenio Europeo de 1950 ha experimentado una notable evolución desde su creación, tanto en oo que se refiere a su extensión como a sus objetivos y procedimientos. Al menos tres fases son visibles en esa evolución: una primera fase, inicialmente orientada a una colaboración interestatal, protagonizada por la Comisión Europea de Derechos Humanos; una segunda fase, centrada en la protección individualizada de los derechos del Convenio por el Tribunal Europeo de Derechos Humanos; y finalmente, parecería apuntarse una tercera, caracterizada por la incipiente adopción de una función cuasi-constitucional del Tribunal de Estrasburgo.

Key words: Human Rights, Euroepan Court of Human Rights, European Convention on Human Rights, Council of Europe.

Palabras clave: Derechos humanos, Tribunal Europeo de Derechos Humanos, Convenio Europeo de Derechos Humanos, Consejo de Europa.

FECHA DE RECEPCIÓN: 10.06.2018

FECHA DE ACEPTACIÓN: 13.09.2018

UNED. Teoría y Realidad Constitucional, núm. 42, 2018, pp. 111-130 